\title{
China's next great leap forward
}

I

$\mathrm{t}$ was a scene that teemed with desperation as 2 brothers in the city of Guangzhou, China, kidnapped a woman and demanded 10000 yuan (\$1633) to pay for their ailing mother's medical expenses.

One brother held a knife to a woman's throat, the other a sign that said "fundraising," during the 2-hour standoff with police, according to local media reports. The woman was later released, unhurt, and the brothers are now in custody.

Police later confirmed that the mother was indeed in hospital, after being seriously hurt when she fell while spraying crops, and needed expensive medical treatment.

It is a drastic example of how far some families will go to help pay for medical expenses here, but also a glimpse into the struggles that many Chinese people face when they fall ill in a country where universal health care is nonexistent and an estimated 9 out of 10 rural residents live without any kind of health insurance.

It's also a situation the government vows to change.

In early April, after years of debate, China's long awaited health care reform blueprint was published - promising to pump 850 billion yuan (\$139 billion) into the health care system by 2011 as part of a longer-term reform package that aims to build a basic health care system by 2020 to provide "safe, effective, convenient and affordable" health services to everyone in rural and urban China.

The blueprint was endorsed by the Central Committee of the Communist Party of China and the nation's cabinet, the State Council, as part of published Guidelines on Deepening the Reform of Health-Care System (http://shs.ndrc.gov .cn/ygjd/ygwj/t20090408_271138.htm).

The need for reform is vital, the guidelines stated. "We must be aware that there is still a rather prominent contradiction between the current development level of China's health care sector

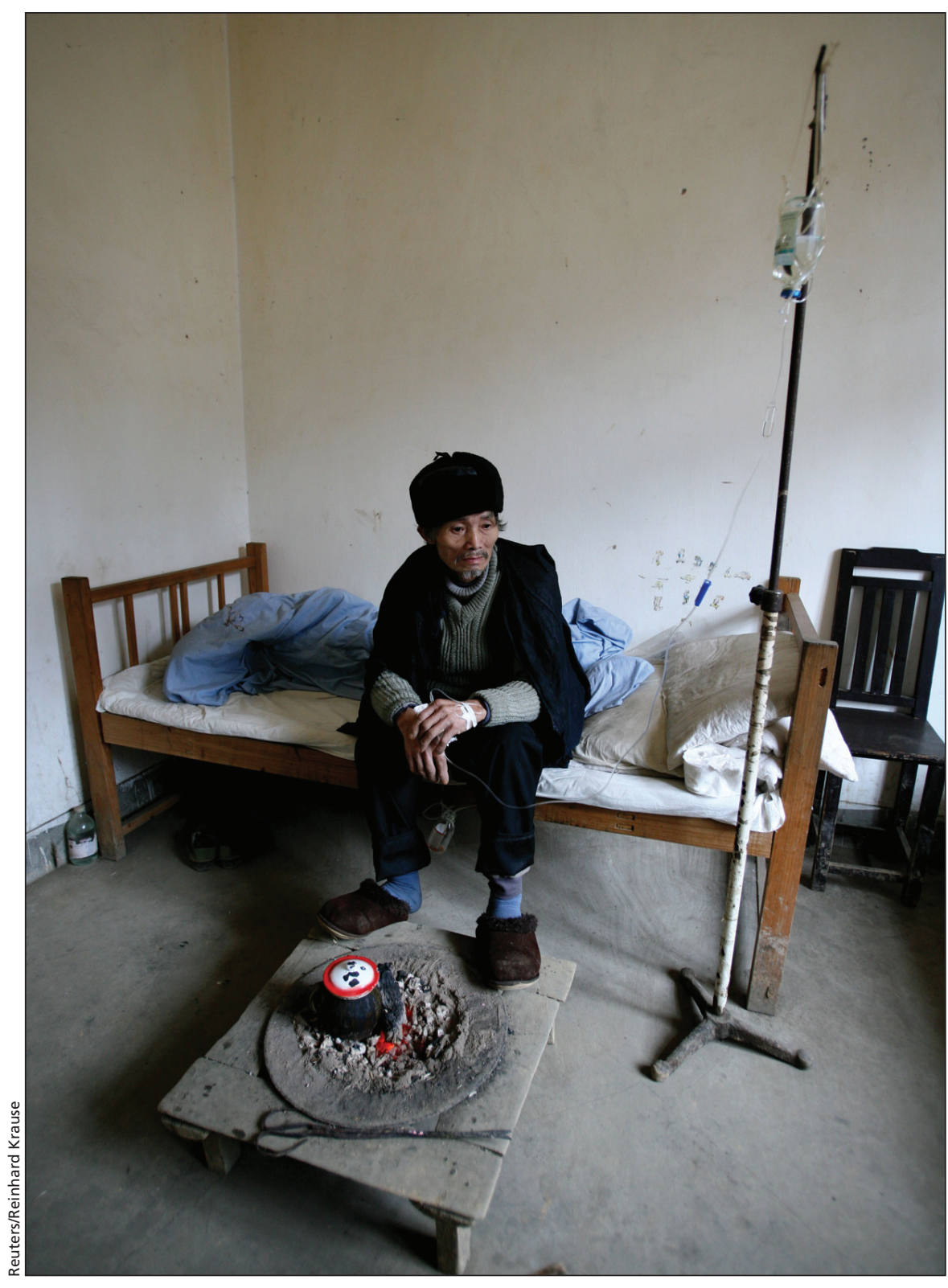

A patient warms himself at a charcoal fire while placed on an intravenous drip at a clinic in Yongli village in China's Guizhou province.

and the people's health demands and the requirements of balanced socio-economic development. Health care undertakings are developing unevenly between urban and rural areas and among different regions; resource allocation is unreasonable; the work of public health as well as rural and community health care is comparatively weak; the medical insurance system is incomplete; pharmaceutical production and circulation order is not well regulated; the hospital managerial system and operational mechanism are imperfect; government investment in health is insufficient; medical costs are soaring, [the] individ- 
ual burden is too heavy, and therefore, the people's reaction is very strong."

The plan is broadly aimed at reinvigorating China's ailing health care system, although it is replete with specifics, including putting a clinic in each of the country's 700000 villages, providing a basic medical package for $90 \%$ of China's 1.3 billion citizens within 3 years, as well as setting price controls on drugs. Currently, an estimated 727 million citizens are covered by medical insurance, so the reforms will almost double coverage.

Other aspects of the plan include pushing newly graduated doctors into the countryside by hiring 1.37 million village doctors and 160000 community doctors, and banning public hospitals from making a profit.

The central government also proposes to go on a health infrastructure spending spree. An estimated 2000 county hospitals and 29000 township hospitals will be built, while 5000 existing townwhip hospitals will be refurbished. The government will also place a clinic in every village within 3 years, while cities will see 3700 community health centres and 11000 community health stations established or upgraded within the same time frame.

However, the central government will only pony up $40 \%$ of the costs. The rest will have to be absorbed by local governments.

It is no small feat to provide health care services to a nation of 1.3 billion people. Most politicians, though, along with the public, herald the plan. But there is some skepticism, particularly among international observers, as to whether the promises can possibly be matched by actual results.

"It is a win for health economists," says Vivian Lin, chair of public health at La Trobe University in Melbourne, Australia. "What we're seeing now is consistent with what has been said before. The most challenging places really are the poor areas, in central and western China. In the coastal areas, as governments became wealthier, the middle class demand and investment for health has also increased."

Overall, there is a huge disparity in China between cities and rural areas. That is exacerbated in regions of cen-

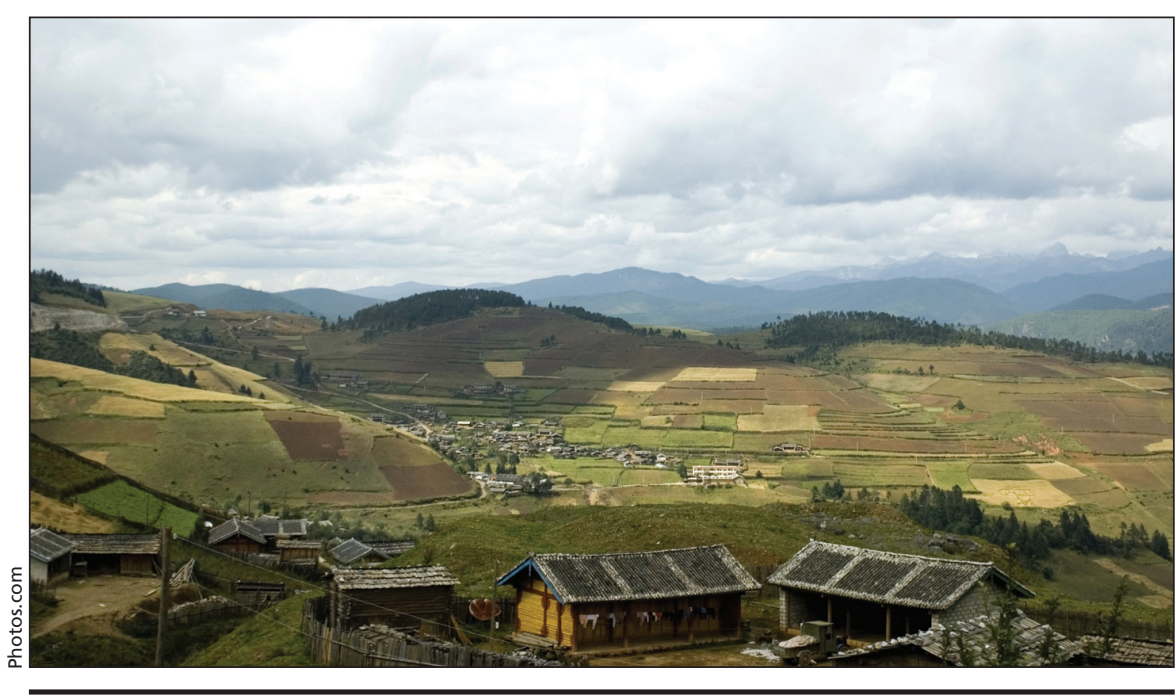

Physicians in rural China typically earn between US\$220-US\$440 per month, which many medical school graduates say is an obstacle to village practice.

tral and western China, where provincial governments are simply unable to generate the kind of funding needed to provide medical care to their citizens.

In some areas, almost all rural residents lack health care coverage and illness can cripple a family, wiping out their savings - if they have any. Reports of patients being turned away at hospitals are rampant and most residents are faced with the reality that their best hope for health care is simply not to get sick.

It wasn't always this way.

During the Maoist era, health care was almost entirely controlled by the government and China was held up by the World Health Organization (WHO) as the model by which developing countries should construct their health systems.

Although not without problems, basic health care was provided to an estimated 9 of 10 urban residents, while rural people had access to subsidized clinics, which were operated by physicians often labelled as "barefoot doctors." Life expectancy soared from 32 in 1950 to 69 by 1985 .

The provision of health services in rural areas was basically 3-tiered: village clinics, town health clinics and county hospitals.

But under Deng Xiaoping's promarket reforms of 1978, privatization of much of the health care system began and the bulk of health care costs were shifted to consumers. The reforms boosted China's economy but basically degraded aspects of its health care system and, by the end of the 1990s China had slid to 188 of 191 countries on the WHO's scale of fairness in medical services.

\section{The current situation}

Perhaps the worst off are migrant workers who travel around the country to perform an array of jobs - from building roads and stadiums to watering plants on the side of the road.

Very few can afford to buy into any sort of health insurance plan, particularly in the current economic climate, in which millions have lost their jobs. The high cost of health care results in most putting off getting care. Some of their costs are reimbursed by the government but generally, they must pay upfront, then apply for reimbursement, which may or may not be approved. The upfront cost is often prohibitory.

Typical is Li Wang, a construction worker in Beijing's wealthy Chaoyang district. "I had an eye infection," he says. "My eye, it was red, it hurt. I waited, but it got worse."

When he finally visited a doctor, he was charged around 80 yuan, which he found difficult to handle on a monthly salary of 1100 yuan.

Wang is hopeful that a new insurance plan will make it easier for him to seek treatment when he needs it. But he frets that the new plan will include premiums that he simply cannot afford. "I 


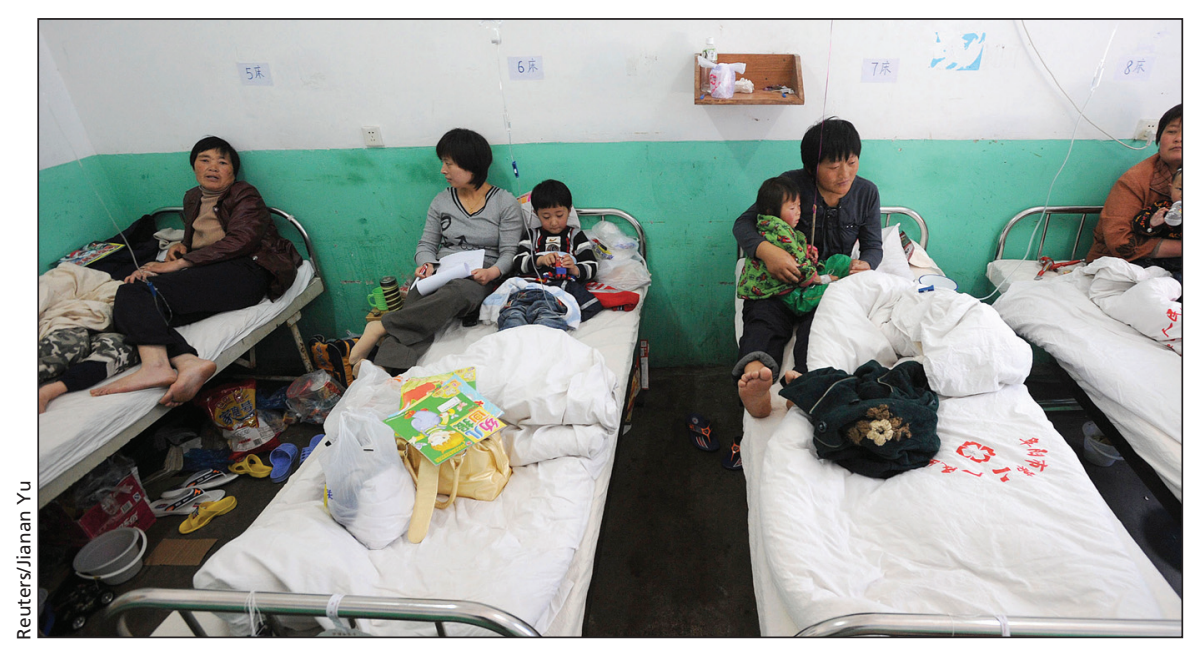

Children receive treatment for an intestinal virus at a hospital in Fuyang, Anhui province.

have to send money home each month," he says. "I don't think I could afford a fee to pay for health."

Whether that will be the case, though, is unknown. The government says the first stage of its health care blueprint will provide $90 \%$ of China's population with some sort of health insurance and it has proposed to subsidize health premiums to the tune of 15 yuan per person per year.

But further details are sparse and it's unclear whether the government will use existing health insurance companies to expand health coverage. There's also been no indication of how comprehensive the government will make the plan or how much the public will actually have to pay for premiums.

\section{The urban brain drain}

Equally problematic is exactly how the government proposes to convince more than 1.3 million doctors to set up a shingle in rural areas. The government is proposing to offer 1.9 million training spots in village and township medical clinics over the next 3 years, and obviously hopes some of those trainees will opt to stay in rural settings. It's also proposing to oblige large urban hospitals to develop cooperative arrangements with at least 3 county-level or township hospitals.

It also proposes to give students a tuition-free medical education if they agree to work in rural clinics for 3 years, while exempting student loans for current graduates if they do the same.
But the success of similar approaches in other nations has been mixed.

The reality is "most of the medical school graduates want to stay in the cities to make a more decent living," says Dr. Yuanli Liu, a senior lecturer on international health at the Harvard University School of Public Health in Boston, Massachusetts, and member of the Expert Committee on Health Policy and Management of the Chinese Ministry of Health.

"Meanwhile, since most of the city hospitals are public hospitals, which do not have liberty to hire as many staff as they want, many graduates end up taking nonmedical jobs, such as working as pharmaceutical industry sales representatives," he adds.

Current pay rates are hardly an adequate incentive. Many village doctors make 1500-3000 Yuan per month.

But pay isn't the only obstacle. Many medical school graduates feel that their hopes for promotion are slim to none in rural areas. As Xiao Yen, a medical student in Nanjing notes, "if I work in the countryside, I will stay there forever. If I stay in a city, then maybe I can get a better job if I work hard."

\section{Controlling drug prices}

Another core element of the central government's health care plan is the bid to control drug prices, which often constitute upward of $50 \%$ of health expenditures.
Doctors, the central government acknowledged in the run-up to unveiling the blueprint, were often aggressively prescribing unnecessary drugs or diagnostic tests to generate income, while hospitals were often inflating the prices charged to patients.

In a bid to constrain those drug costs, the government will establish a list of "essential medicines" that it will begin producing and distributing.

The list has yet to be published, but officials from the Ministry of Health estimate that between 300 to 400 drugs - recommended by the WHO — will make the final cut for government production lines. The WHO has been listing essential medicines since 1977. The drugs included are those that are the "most efficacious, safe and cost-effective" for priority conditions, according to the WHO's 15th list (www.who.int).

Under the health care overhaul, the government also plans to fix reference prices for those drugs. Provincial governments will set purchase prices, but it's believed the measures will limit artificial or deliberate inflation of charges to consumers. Under the blueprint, essential medicines must be used at all public health facilities commencing in 2009.

\section{More details needed}

For now, while most applaud the intentions of health care reform in China, it's entirely unclear how much can be delivered. Of particular concern is whether local governments can and will adhere to the regulations set out by the central government, and open their vaults for health care.

What is clear, though, is the tremendous desire and appetite for change. Even the state news agency Xinhua cited "public criticism" as the impetus for government action.

Indeed, health care reform ranks high on the list of concerns of Chinese citizens. Many have lost their life savings due to illness or have been turned away at hospitals for being unable to pay. That concern is unlikely to abate as details emerge on the government's plans. - Katie Lewis, Beijing, China

DOI:10.1503/cmaj.090926 